\title{
Electrochemical Deposition of Hollow N-Substituted Polypyrrole Microtubes from an Acoustically Formed Emulsion
}

\author{
Conor P. McCarthy, ${ }^{*}{ }^{\dagger}$ Niall B. McGuinness, ${ }^{\dagger}$ Patrick B. Carolan, ${ }^{\ddagger}$ Catherine M. Fox, ${ }^{\dagger}$ \\ Bernadette E. Alcock-Earley, ${ }^{\dagger}$ Carmel B. Breslin, ${ }^{\dagger}$ and A. Denise Rooney ${ }^{\dagger}$ \\ ${ }^{\dagger}$ Department of Chemistry, National University of Ireland Maynooth, Maynooth, Co. Kildare, Ireland \\ ${ }^{\ddagger}$ Materials Chemistry and Analysis Group, Tyndall National Institute, Co. Cork, Ireland
}

Supporting Information

ABSTRACT: We outline an electrodeposition procedure from an emulsion to fabricate novel vertically aligned open and closed-pore microstructures of $\operatorname{poly}(\mathrm{N}$-(2-cyanoethyl)pyrrole) (PPyEtCN) at an electrode surface. Adsorbed toluene droplets were employed as soft templates to direct polymer growth. The microstructures developed only in the presence of both $\mathrm{ClO}_{4}^{-}$and $\mathrm{H}_{2} \mathrm{PO}_{4}^{-}$doping ions due to a slower rate of polymer propagation in this electrolyte. Two sonication methods (probe and bath) were used to form the emulsion, producing significantly different microstructure morphologies. Control over microtube diameter can be achieved by simply altering the emulsion sonication time or the amount of toluene added to form the emulsion. Electrochemical characterization

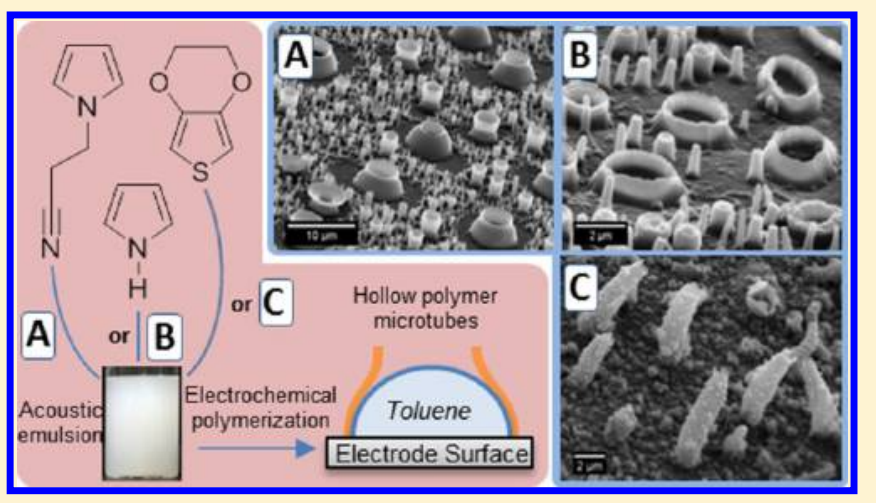
indicated the PPyEtCN microtube morphology had an increased electrochemical response compared to its bulk counterpart. TEM analysis of individual closed-pore microtubes identified a hollow interior at the base within which the toluene droplet was encapsulated. This cavity may be used to entrap other compounds making these materials useful in a range of applications. The methodology was also applied to form microstructures of poly(3,4-ethylenedioxythiophene) and polypyrrole.

\section{INTRODUCTION}

There has been extensive research focusing on methods to control the growth of conducting polymers, as many studies have illustrated that their physical properties are a consequence of their morphology. ${ }^{1,2}$ Hollow nano/micro-structured conducting polymeric materials are a rapidly developing research topic due to the significant range of applications for which they are suited, including drug delivery, sensing, separation, encapsulation, catalysis, and as nanoreactors. ${ }^{3-7}$ Polypyrrole (PPy) is one of the most extensively studied conducting polymers as it is facile to prepare and has a range of useful properties which include fast redox activity, ${ }^{8}$ good ion exchange capabilities, ${ }^{9}$ and biocompatibility. ${ }^{10}$ Much recent attention has focused on the design and fabrication of PPy into hollow openpore nano/microtubes ${ }^{11-14}$ or hollow closed-pore nano/ microspheres ${ }^{15,16}$ as these structures have potential application in controlled drug delivery systems. A number of authors, with particular reference to the work of Shi and co-workers, have developed electrodeposition methods to form hollow open tubular PPy structures anchored to substrate materials, which allows greater control over their use. ${ }^{6,17-20}$ Furthermore, the permeability of conducting polymers can be altered as a function of applied potential or $\mathrm{pH}^{21}$ and this property has been exploited to encapsulate and subsequently release guest species from within PPy microcontainers. ${ }^{22}$
While the nano/micro morphologies of conducting polymers have been comprehensively studied, very little work has been performed with their covalently functionalized counterparts. The development of functionalized conducting polymers in controlled morphologies was highlighted as an important future research area by Shi and co-workers in their review on nanostructured conducting polymers. ${ }^{23}$ In our previous work, we developed an electrochemical template-free procedure to form a novel poly(N-(2-cyanoethyl)pyrrole) (PPyEtCN) film in a nanowire morphology. ${ }^{24} \mathrm{~A}$ number of other studies have been reported using electrochemical or chemical approaches to form microstructures of $\mathrm{N}$-functionalized PPy. Examples of note include the electrodeposition of poly $(N$-methylpyrrole) (PPyMe) microstructures in a "doughnut" morphology using a $\mathrm{H}_{2}$ bubble template carried out by Teixeira-Dias et al. ${ }^{25}$ and the development of PPyEtCN and PPyMe microspheres through chemical oxidation on polystyrene core particles by Alemán and co-workers. ${ }^{26,27}$ Electrodes modified with covalently functionalized conducting polymers have been utilized in sensor applications as the moieties at the substituted position enable supramolecular interactions with other molecules. For example, PPyEtCN modified electrodes have been used to immobilize

Received: December 4, 2012

Revised: January 20, 2013

Published: February 1, 2013 
specific antibodies for the fabrication of biosensors ${ }^{28}$ and in the electrochemical sensing of dopamine. ${ }^{29}$ Alternatively, the functional group can be chemically modified in order to covalently attach a wide range of species to the polymer surface which include carbon nanotubes, ${ }^{30}$ biomolecules, ${ }^{31}$ or fluorinated alkyl chains. ${ }^{32}$

There is a growing interest in preparing PPy nano/ microstructures employing facile template-free or soft-template electrochemical approaches. ${ }^{33-35}$ The advantage of these methodologies is that the steps to construct and then subsequently dissolve the hard templates are not required. Furthermore, the morphology of the polymer formed can be controlled by simply altering the electrochemical conditions. Previously, a number of authors have reported using nano/ micro monomer droplets to deposit conducting polymers on electrode surfaces..$^{20,36,37}$ However, these methodologies require very high concentrations of monomer and the modification of the electrode surface or the addition of a surfactant. Interestingly, Mazur and co-workers have developed an elegant interfacial chemical oxidation polymerization method using either organic or aqueous solvent microdroplets to entrap either hydrophobic ${ }^{38}$ or hydrophilic ${ }^{16}$ compounds within PPy microvessels. Herein, we report the first application of this solvent microdroplet method in an electrochemical polymerization reaction.

Using adsorbed toluene droplets as soft templates in conjunction with the mixed electrolyte cosolvent system we have previously employed for the template-free electrodeposition of PPyEtCN nanowires, a novel means has been developed to electrochemically fabricate PPy-based microtubes and microcontainers. This article, to the best of our knowledge, is the first report of the electrochemical deposition of microscale tubular structures of PPyEtCN, in which the tubes are anchored to an electrode surface. Although we have chosen PPyEtCN for these studies, our system can be used to design similar structures for other monomers in which an organic/ aqueous based solvent system may be employed.

\section{EXPERIMENTAL SECTION}

Preparation of Emulsion. All chemicals were purchased from Sigma-Aldrich and were of analytical grade. $\mathrm{N}$-(2-Cyanoethyl)pyrrole (PyEtCN) was distilled under vacuum and stored under nitrogen at $-40{ }^{\circ} \mathrm{C}$. In a typical experiment $\mathrm{LiClO}_{4}(20 \mathrm{mM})$ and $\left(\mathrm{NH}_{4}\right) \mathrm{H}_{2} \mathrm{PO}_{4}$ $(100 \mathrm{mM})$ were dissolved in a water:ethanol $(7: 3)$ solution. Toluene $(80 \mu \mathrm{L})$ and $\operatorname{PyEtCN}(56 \mathrm{mM})$ were added to $10 \mathrm{~mL}$ of this solution by a micropipet. This suspension was shaken vigorously and then sonicated using a probe sonicator (Bandelin Sonoplus HD2200, MS72 tip) for $1 \mathrm{~min}$ at $20 \%$ of maximum power, or the suspension was stirred vigorously and then sonicated in an ultrasonic bath (Fisher Scientific FB 15048) for $1 \mathrm{~min}$.

Polymerization. Electrochemical experiments were performed using a Solatron 1285 potentiostat at room temperature. A standard three-electrode cell was employed using a platinum mesh as an auxiliary electrode, while the working electrode was a glassy carbon rod embedded in a Teflon holder using an epoxy resin. All potentials were measured against a saturated calomel electrode (SCE) reference. Electrode surfaces were prepared by mechanical polishing on emery paper using 6 and $1 \mu \mathrm{m}$ diamond suspensions lubricated with water, then sonicated in ethanol between each polishing, and finally sonicated in ethanol and water, respectively. Before polymerization the electrodes were left to sit in the emulsion for $5 \mathrm{~min}$ to allow the toluene to adsorb to the surface. In a typical experiment an oxidative potential of $0.95 \mathrm{~V}$ was applied for $3 \mathrm{~min}$; the polymers were then washed with ethanol and water and dried by air flow before further characterization.
Characterization. SEM analysis was performed using a Hitachi S3200-N with a tungsten filament electron source, and the resulting images were analyzed using ImageJ software. Before analysis samples were dried using a $\mathrm{N}_{2}$ flow and then sputter-coated under argon using an $\mathrm{Au} / \mathrm{Pd}$ target. A thickness monitor was employed to obtain a coating of $15 \mathrm{~nm}$. TEM was performed using a JEOL 2100 with a LaB6 filament operating at $200 \mathrm{kV}$. Samples were prepared by removing the polymer from the substrate using a surgical blade and then sonicating in ethanol for $10 \mathrm{~min}$. For light microscopy, the emulsions were prepared with the addition of a red dye (Sudan IV, $0.005 \%$ wt toluene) which was added to the toluene before its addition to the emulsion solution. This allowed the droplets to be more easily identified. Several drops of this solution were pipetted onto a glass slide, and images were recorded using an Olympus BX161 optical microscopy with $\mathrm{Cell}^{\mathrm{F}}$ analysis software. Contact angle experiments employed a static water droplet of $1 \mu \mathrm{L}$ using an OCA 20 from Dataphysics Instruments. For FTIR characterization samples were made into $\mathrm{KBr}$ disks, and spectra were recorded using a PerkinElmer 2000 spectrometer.

\section{RESULTS AND DISCUSSION}

When sufficient energy was applied to the toluene/water/ ethanol system, through ultrasonication, it was possible to create a homogeneous dispersion of toluene microdroplets within the continuous phase. This turbidity could be maintained for several hours without the need for any surfactants or stabilizers. This is a key factor in utilizing this system as a soft template method, as the absence of stabilizing agents leaves the toluene microdroplets available to adsorb to solid surfaces. ${ }^{39}$ The electrochemical polymerization mixture, $\mathrm{LiClO}_{4}(20 \mathrm{mM}),\left(\mathrm{NH}_{4}\right) \mathrm{H}_{2} \mathrm{PO}_{4}(100 \mathrm{mM}), \operatorname{PyEtCN}(56$ $\mathrm{mM})$, and toluene $(80 \mu \mathrm{L})$ in $10 \mathrm{~mL}$ of water/ethanol (7:3), was emulsified using two methods (Scheme 1). The mixture

Scheme 1. (A) Multiphasic Starting Solution of Toluene with $\mathrm{H}_{2} \mathrm{O} / \mathrm{EtOH} / \mathrm{PyEtCN}$; Resultant Emulsions from (B) Shaking and Probe Sonication and (C) Stirring and Bath Sonication; (D) Resulting Solution of $\mathrm{H}_{2} \mathrm{O} / \mathrm{EtOH} / \mathrm{PyEtCN}$ in the Absence of Toluene

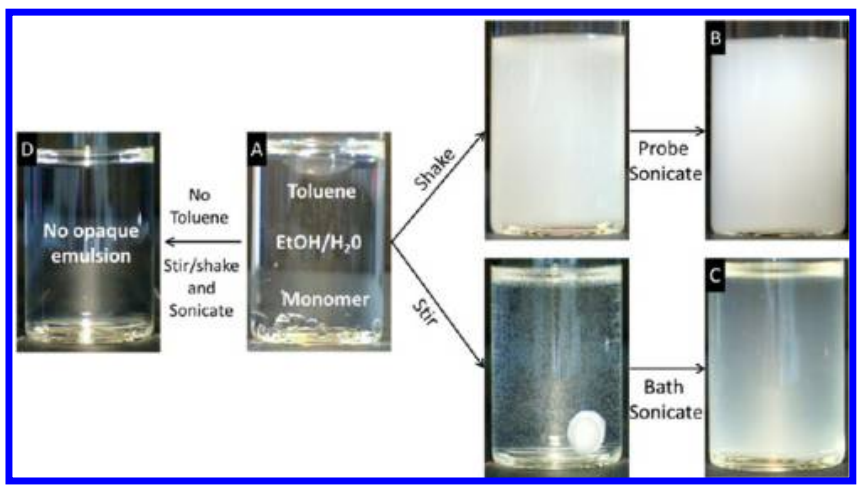

was either shaken vigorously and then sonicated for $1 \mathrm{~min}$ using an ultrasonic probe or stirred vigorously for $5 \mathrm{~min}$ and then sonicated for 1 min using an ultrasonic bath (Schemes $1 \mathrm{~B}$ and 1C, respectively). In both cases the solution went from a transparent multiphasic system to an opaque emulsion. However, the emulsion formed using the ultrasonic probe was much more opaque and possessed a longer period of stability than that formed employing the ultrasonic bath. Previous studies, regarding the formation of emulsions, have shown that the use of an ultrasonic probe compared to an ultrasonic bath results in more stable emulsions consisting of smaller sized oil droplets. ${ }^{40}$ In the absence of toluene no 


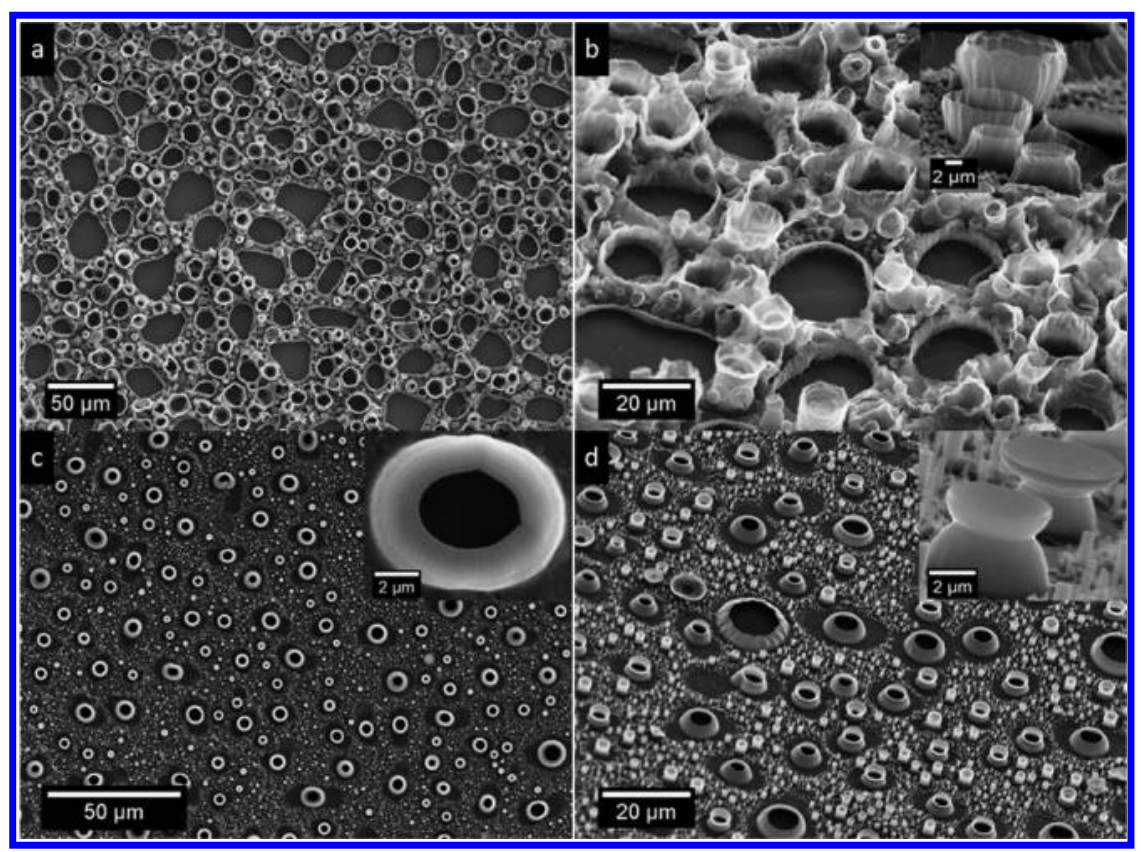

Figure 1. SEM micrographs of PPyEtCN microstructures deposited at $0.95 \mathrm{~V}$ from $10 \mathrm{~mL}$ of (a, b) water and (c, d) water/ethanol (7:3). Emulsion contained PyEtCN $(56 \mathrm{mM}), \mathrm{LiClO}_{4}(20 \mathrm{mM}),\left(\mathrm{NH}_{4}\right) \mathrm{H}_{2} \mathrm{PO}_{4}(100 \mathrm{mM})$, and toluene $(80 \mu \mathrm{L})$ with 1 min sonication by probe.

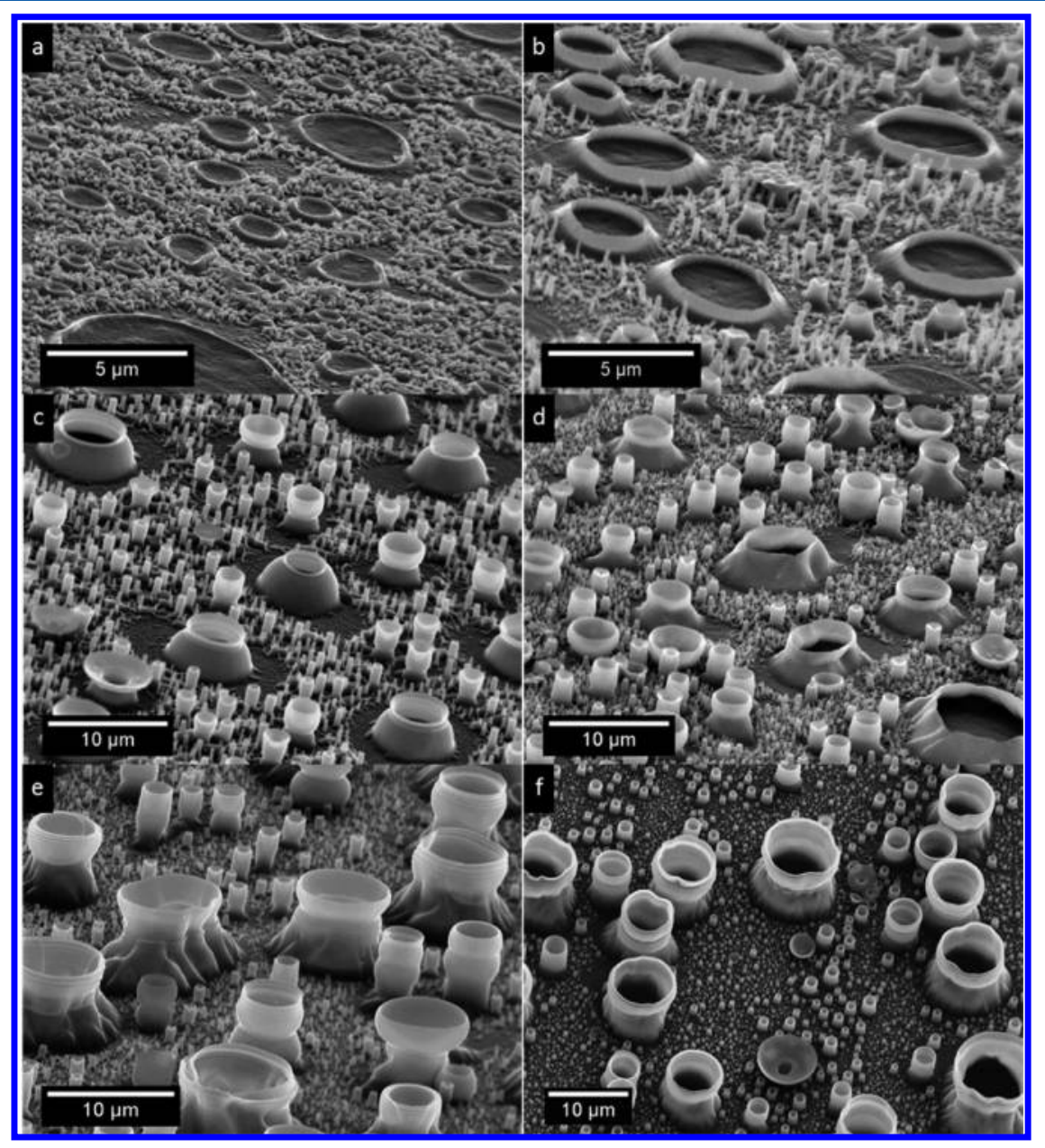

Figure 2. SEM micrographs of PPyEtCN microstructures deposited at (a) 0.85, (b) 0.90, (c) 0.95, (d) 1.00, (e) 1.10 , and (f) $1.20 \mathrm{~V}$ for 3 min. Emulsion contained PyEtCN $(56 \mathrm{mM}), \mathrm{LiClO}_{4}(20 \mathrm{mM}),\left(\mathrm{NH}_{4}\right) \mathrm{H}_{2} \mathrm{PO}_{4}(100 \mathrm{mM})$, and toluene $(80 \mu \mathrm{L})$ in $10 \mathrm{~mL}$ of water/ethanol $(7: 3)$ with 1 min sonication by probe. 


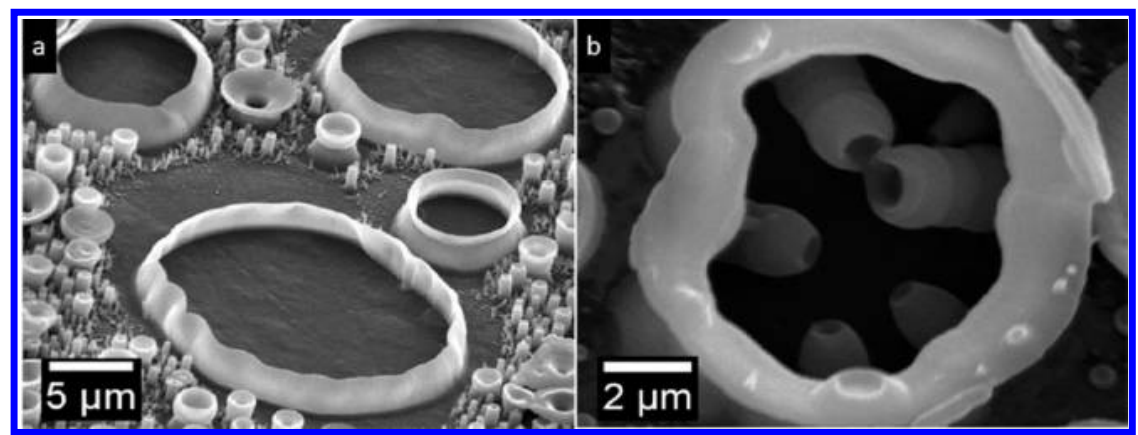

Figure 3. SEM micrograph of PPyEtCN microstructures deposited at $0.95 \mathrm{~V}$ for (a) $5 \mathrm{~min}$ and (b) $30 \mathrm{~min}$. Emulsion contained PyEtCN ( $56 \mathrm{mM}$ ), $\mathrm{LiClO}_{4}(20 \mathrm{mM}),\left(\mathrm{NH}_{4}\right) \mathrm{H}_{2} \mathrm{PO}_{4}(100 \mathrm{mM})$, and toluene $(80 \mu \mathrm{L})$ in $10 \mathrm{~mL}$ of water/ethanol (7:3) with $45 \mathrm{~s}$ sonication by probe.

opaque emulsion (droplets with diameter $>0.1 \mu \mathrm{m}$ ) was formed (Scheme 1D). When the microdroplets adsorbed on an electrode surface, it was then possible to use them as templates for an electrochemical anodic polymerization of PyEtCN into a range of microstructures.

Interestingly, PyEtCN polymerized from a toluene/water emulsion in the absence of ethanol produced incomplete films. The formation of microtubes occurred, but there were large areas $(20-50 \mu \mathrm{m}$ in diameter) across the electrode surface which had total absence of polymer growth (Figure 1a). Moreover, as Figure $1 \mathrm{~b}$ illustrates, the tubes formed in a highly irregular fashion with varying heights and diameters. A homogeneous distribution of microtubes was only formed when ethanol was added to the system as a cosolvent, as seen in Figure $1 \mathrm{c}, \mathrm{d}$. Here, the tubes possess a smooth exterior and have a uniform size distribution. It is also clear that the structures had an empty cavity in the center and were hollow through to the substrate surface (Figure 1c (inset)). Confirmation that the cyano group was still intact after polymerization was obtained by the presence of the characteristic $v(\mathrm{C} \equiv \mathrm{N})$ band at 2251 $\mathrm{cm}^{-1}$ in the FTIR spectrum recorded of the polymer film (see Supporting Information Figure 1).

In a typical polymerization experiment the emulsion was formed using the ultrasonic probe, and it was observed that microtubes were produced between the range of oxidation potentials studied $(0.85-1.30 \mathrm{~V})$; below this potential no growth was obtained. It was also possible to electrodeposit the microtubes on different substrates such as $\mathrm{Au}, \mathrm{Pt}$, and indiumtin oxide. Furthermore, the orientation of the electrode within the cell did not negatively affect microtube growth or their coverage over the electrode surface. Regardless of applied potential, it was the adsorbed toluene droplets which influenced growth to create a tubular morphology. However, the applied electrical potential determined the rate at which the tubes formed and this was found to influence the shape of the hollow tube structure (Figure 2). At a relatively low potential $(0.85 \mathrm{~V}$, Figure 2a) platelike structures were formed which had very little vertical growth; this has also been seen by other researchers. ${ }^{19}$ As the potential was increased from 0.90 to $1.00 \mathrm{~V}$ in $50 \mathrm{mV}$ increments (Figures $2 \mathrm{~b}, 2 \mathrm{c}$, and $2 \mathrm{~d}$ respectively), the final morphology resembled a more bowllike structure, as the polymer took the shape of the adsorbed toluene droplet to a greater extent. Furthermore, the polymer growth extended in a vertical direction, and the tubes increased in height; this has also been observed for other PPy microtube systems. ${ }^{17,19}$ At higher oxidation potentials of 1.10 and $1.20 \mathrm{~V}$ (Figures $2 \mathrm{e}$ and $2 \mathrm{f}$ ) the tubes had increased substantially in height but were also observed to have an increase in diameter at their openings.

Upon inspection of the PPyEtCN microtubule SEM micrographs, it can be seen that the areas immediately surrounding the microtubes showed very little polymerization (Figure 3a). In the toluene/water emulsion chemical oxidation experiments carried out by Mazur and co-workers, it was clear that most of the pyrrole monomer resided inside the toluene droplets, as polymerization only occurred at the surface of the droplets and not in the bulk solution. ${ }^{38}$ In the present system, the microtubes formed preferentially in large numbers over the electrode surface as the main structures. However, away from these sites a thin layer of bulk polymer observed. On the basis of these observations, it was apparent that a proportion of the PyEtCN monomer was contained within the toluene droplets, with some monomer remaining free in solution. As the duration of sonication time was increased, the average diameter of the tubes decreased. This observation is consistent with the known literature regarding droplet size as a function of sonication time, ${ }^{40}$ and it allows a means of controlling the diameters of the tubes. Interestingly, for prolonged periods of growth (30 min) a second stage of microtube nucleation was observed, yielding smaller tubes developing within the larger tubes (Figure $3 \mathrm{~b}$ ). Growth of these smaller microtubes always evolved from the inner walls of the bigger microtubes and was never observed occurring from the base center. This indicated that the toluene droplets had adhered strongly to the substrate throughout the polymerization process and prohibited further growth at these sites. It also highlighted the stability of the emulsion prepared by this method.

A schematic illustrating the proposed mechanism of microtube formation is displayed in Scheme 2. Here the toluene droplet can be seen adsorbed to the electrode surface,

Scheme 2. Formation Mechanism of PPyEtCN Microtubes

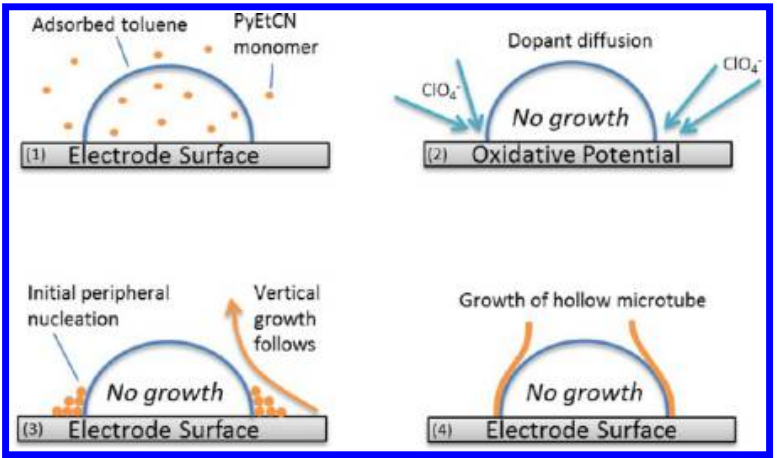


containing some monomer which is distributed between the continuous phase of the emulsion and the toluene droplet (1). Once an oxidative potential is applied, dopant from the surrounding bulk solution diffuses toward the adsorbed droplet (2). Growth proceeds favorably at the surface of the droplet because a high electric field originates here due to edge effects. $^{20}$ In addition, at this interface both monomer and dopant are present in sufficient quantities to enable polymerization to proceed (3). Finally, polymer growth mimics the shape of the original droplet leaving a hollow interior (4).

The diameters of the toluene emulsion droplets and polymer microtubes were compared to confirm that the addition of the toluene was responsible for the microtube morphology. A typical emulsion was formed, and several drops were placed on a glass slide and allowed to adsorb for $5 \mathrm{~min}$, before imaging was performed using an optical microscope (Figure 4a).

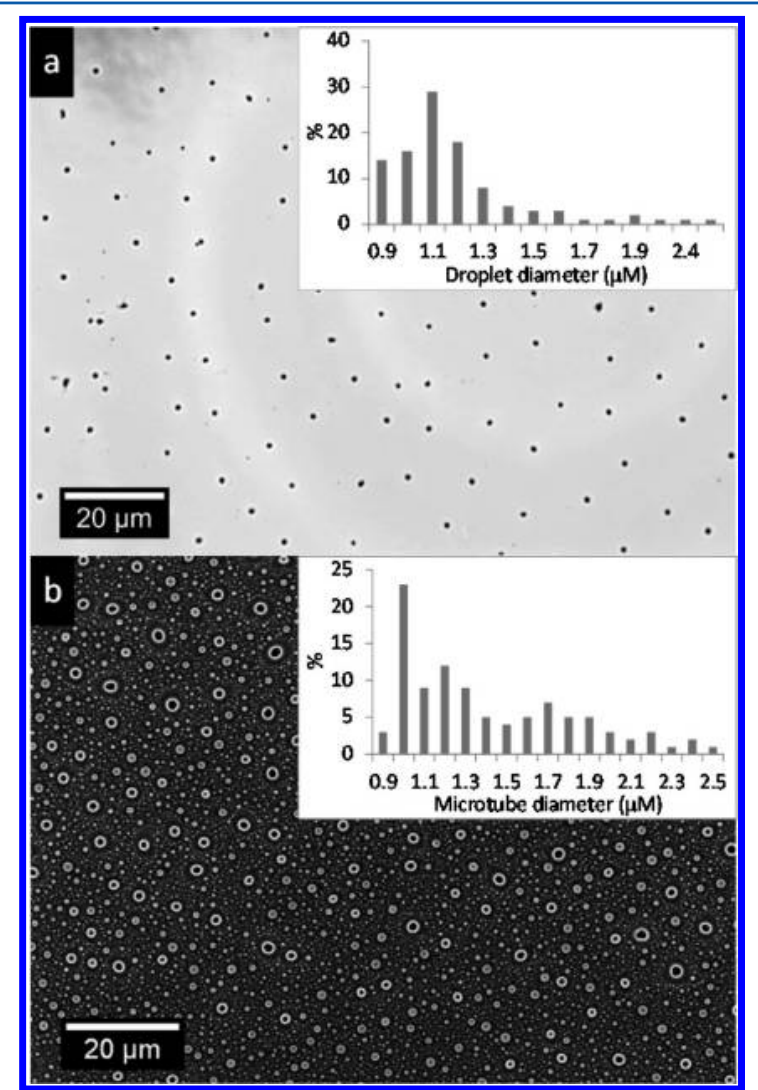

Figure 4. (a) Optical microscope and (b) SEM micrographs of emulsion droplets and polymer microstructures, respectively, with inset of diameter vs percentage of droplets/microtubes. Emulsion contained PyEtCN (56 mM), $\mathrm{LiClO}_{4}(20 \mathrm{mM}),\left(\mathrm{NH}_{4}\right) \mathrm{H}_{2} \mathrm{PO}_{4}(100$ $\mathrm{mM})$, and toluene $(80 \mu \mathrm{L})$ in $10 \mathrm{~mL}$ of water/ethanol (7:3) with 1 min sonication by probe.

Similarly, an SEM micrograph was recorded of a polymer film formed from an identical emulsion (Figure $4 \mathrm{~b}$ ). The diameters of the droplets and polymer microtubes were then measured, and the distribution of their sizes is given in Figure $4 \mathrm{a}$ (inset) and $4 \mathrm{~b}$ (inset), respectively. Given the significant difference in resolution between the microscopes used, there was still a good correlation between the droplet size and the microtube diameter. The average diameter of the adsorbed toluene droplet was $1.00 \mu \mathrm{m}$ while the average diameter of the microtubes was $1.44 \mu \mathrm{m}$. Considering the typical thickness of the microtube walls was $\sim 200 \mathrm{~nm}$, these values are consistent with each other. These results confirmed that the toluene droplets do in fact act as the templates for the microtube formation.

The electrolyte mixture $\left(\mathrm{LiClO}_{4}(20 \mathrm{mM}) /\left(\mathrm{NH}_{4}\right) \mathrm{H}_{2} \mathrm{PO}_{4}\right.$ $(100 \mathrm{mM}))$ was chosen as previous studies regarding nanowire formation have indicated that this type of system promotes the growth of PPy nanowires in the direction perpendicular to the electrode surface. ${ }^{24,35,41}$ However, to the best of our knowledge, this is the first report utilizing this type of electrolyte system to form hollow PPy-based microstructures. It has been proposed that the role of the $\mathrm{HPO}_{4}{ }^{2-}$ or $\mathrm{H}_{2} \mathrm{PO}_{4}{ }^{-}$anions during electrochemical deposition of PPy nanowires is to control the vertical growth by acting as a scaffolding agent through $\mathrm{H}$ bonding between the PPy chains. ${ }^{35}$ However, interestingly, Debiemme-Chouvy determined that during the electrochemical deposition of PPy nanowires from $\mathrm{NaClO}_{4}(1 \mathrm{mM}) / \mathrm{Na}_{2} \mathrm{HPO}_{4}$ $(200 \mathrm{mM})$ solution the $\mathrm{ClO}_{4}^{-}$anion was preferentially incorporated into the polymer to balance the positive charges on the polymer chains. ${ }^{41}$ She proposed that when amphoteric $\mathrm{HPO}_{4}{ }^{2-}$ anions are in close proximity to the propagating polymer they become protonated by the $\mathrm{H}^{+}$cations which are expelled during polymer formation. This would produce phosphoric acid which is uncharged $\left(\mathrm{pK}_{\mathrm{a}}\right.$ of $\mathrm{H}_{3} \mathrm{PO}_{4}$ is 2.6) and therefore would not partake in doping of the polymer backbone. A similar effect was observed in the present system as $\mathrm{H}_{2} \mathrm{PO}_{4}{ }^{2-}$ did not efficiently support polymerization, as shown in Figure 5a, curve 1 . Here, the polymer growth profile in a $\left(\mathrm{NH}_{4}\right) \mathrm{H}_{2} \mathrm{PO}_{4}(100 \mathrm{mM})$ emulsion containing no $\mathrm{LiClO}_{4}$ is shown; upon application of the oxidizing potential the current density remained very small and dropped as a function of time. The SEM recorded at the end of the process showed no evidence of polymer formation. In contrast, when $\mathrm{LiClO}_{4}(20$ $\mathrm{mM}$ ) was added to the same polymerization mixture, the growth profile (Figure 5a, curve 2) displayed a significantly larger current density, indicating an electrochemical reaction was taking place. The first part of the growth curve followed the increase in current density observed for electrolyte systems containing solely $\mathrm{LiClO}_{4}$ (Figure 5a, curve 3). However, at ca. $20 \mathrm{~s}$ the curve reached a maximum and the rate of polymerization decreased down to a plateau at ca. $80 \mathrm{~s}$, which is typical of systems containing a hydrogen phosphate electrolyte. ${ }^{41}$ The SEM recorded of this electrode after $300 \mathrm{~s}$ of growth showed the polymer microtubular structures (Figure 5c). Additionally, nucleation of the polymer occurred around each toluene droplet simultaneously, as the sides of each tube were observed to be identical in height. Analysis using EDX indicated that the $\mathrm{ClO}_{4}^{-}$was the preferred dopant as the microtubes were found to contain approximately equal amounts of phosphorus/chlorine despite the 5:1 ratio of phosphorus/chlorine in the electrolyte mixture (see Supporting Information Figure 2). When polymerization was performed using only $\mathrm{LiClO}_{4}(20 \mathrm{mM})$ as the electrolyte, a much more rapid polymerization was observed in the growth profile (Figure 5a, curve 3), resulting in bulk polymer forming around the adsorbed toluene droplets (Figure 5b). This identified that reaction conditions which led to a fast rate of polymerization were not favorable for producing vertical polymer growth, perpendicular from the electrode surface.

Using a mixed $\mathrm{LiClO}_{4} /\left(\mathrm{NH}_{4}\right) \mathrm{H}_{2} \mathrm{PO}_{4}$ electrolyte system provided control over the rate of the polymerization. A number of reports have shown that controlling the kinetics of polymerization, during electrochemical deposition, is the key to growing conducting polymers in an ordered morphology. In 


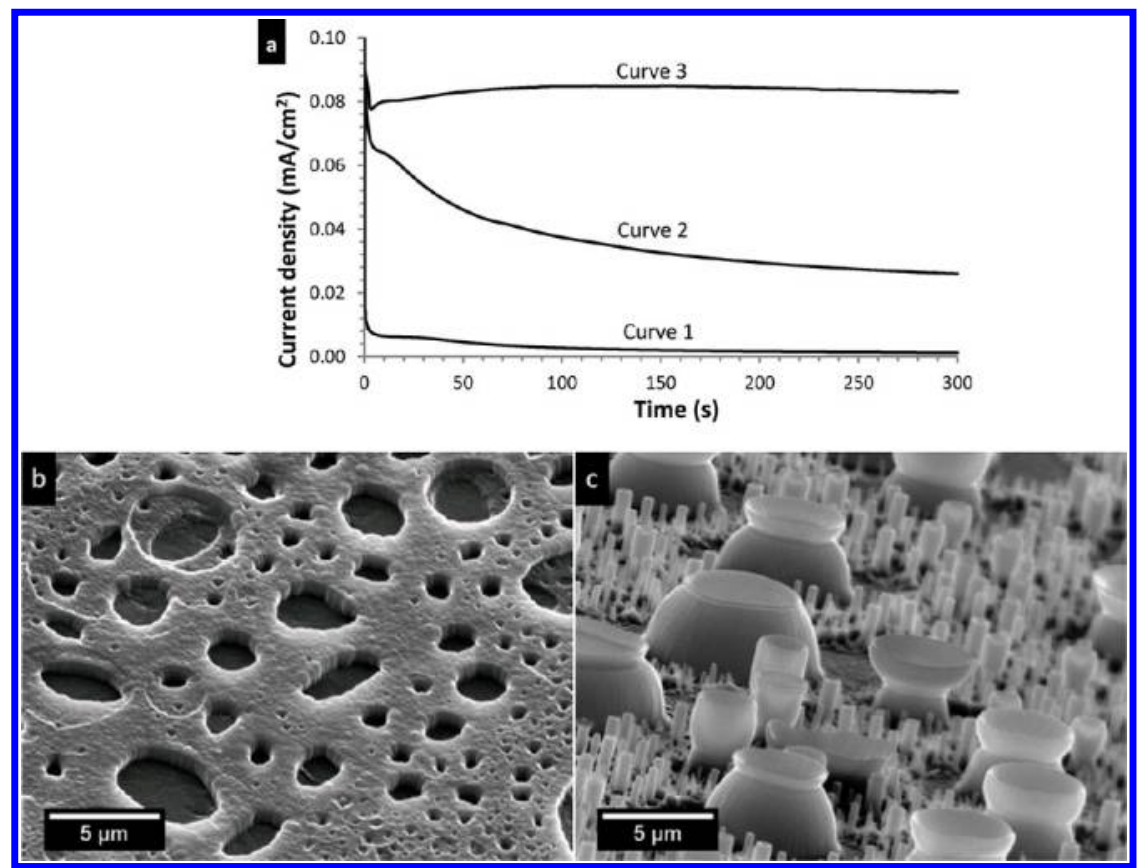

Figure 5. (a) Polarization profile of PPyEtCN polymers deposited from an emulsion containing PyEtCN $(56 \mathrm{mM})$ and toluene $(80 \mu \mathrm{L})$ in $10 \mathrm{~mL}$ water/ethanol (7:3) with $1 \mathrm{~min}$ sonication by probe. Electrolytes: curve $1,\left(\mathrm{NH}_{4}\right) \mathrm{H}_{2} \mathrm{PO}_{4}(100 \mathrm{mM})$; curve 2, $\mathrm{LiClO}_{4}(20 \mathrm{mM})$ with $\left(\mathrm{NH}_{4}\right) \mathrm{H}_{2} \mathrm{PO}_{4}$ $(100 \mathrm{mM})$; and curve 3, $\mathrm{LiClO}_{4}(20 \mathrm{mM})$. Oblique-angle view SEM micrographs b and $\mathrm{c}$ of resulting polymers from (a), curve 3 and curve 2, respectively.

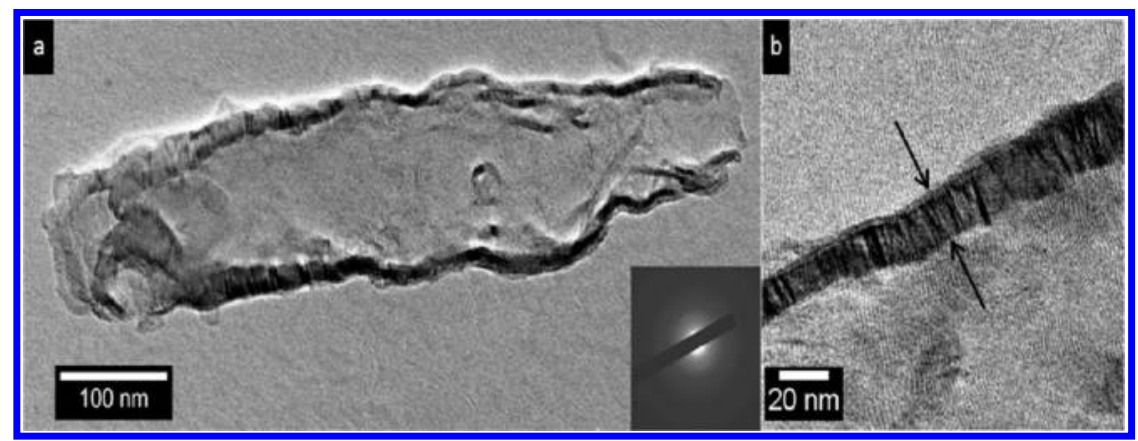

Figure 6. (a) TEM micrograph of individual PPyEtCN tube and (b) magnification of exterior wall area of tube. Emulsion contained PyEtCN (56 $\mathrm{mM}), \mathrm{LiClO}_{4}(20 \mathrm{mM}),\left(\mathrm{NH}_{4}\right) \mathrm{H}_{2} \mathrm{PO}_{4}(100 \mathrm{mM})$, and toluene $(80 \mu \mathrm{L})$ in $10 \mathrm{~mL}$ of water/ethanol $(7: 3)$ with 1 min sonication by probe.

these studies the applied current density was reduced in a stepwise fashion to allow for fast initial nucleation followed by slow propagation, yielding uniformly orientated conducting polymer nanowires/tubes. ${ }^{20,42}$ In the present system it is clear from the growth curve (Figure 5a, curve 2) that the initial stage of the polymerization was also rapid. However, this initial fast growth rate was not maintained due to the presence of $\mathrm{H}_{2} \mathrm{PO}_{4}^{-}$. We propose that the role of the $\mathrm{H}_{2} \mathrm{PO}_{4}{ }^{-}$ion was to prevent an increase in $\mathrm{H}^{+}$ion concentration close to the polymer surface as the polymer propagated. Studies have shown that the rate of polymerization of pyrrole increases under acidic conditions. ${ }^{43}$ TEM micrographs recorded of individual tubes show that the hollow cavity extends the entire length of the structure (Figure 6a). It also confirmed that the tube morphology remained intact despite being removed from the surface and sonicated, indicating high structural stability. High-magnification TEM analysis of the outer walls showed that there was dense packing of polymer surrounding the hollow interior (Figure $6 \mathrm{~b}$ ). The high density of the polymer in the tube walls most likely arises due to the combination of the slow rate of polymer propagation combined with the preferential polymerization at the droplet surface. The electron diffraction pattern, which was a diffusive ring, identified the microtubes as having an amorphous structure (Figure 6a inset).

Water contact angle measurements carried out on both the bulk and microtubule PPyEtCN films resulted in average values of $19^{\circ}$ and $38^{\circ}$, respectively, indicating that both films had superhydrophilic properties. This has previously been shown for N-substituted PPy films containing a polar functional group. ${ }^{44}$ Cyclic voltammograms were recorded of both a PPyEtCN microtubule film and a bulk PPyEtCN film grown in the absence of toluene (Figure 7). As can be observed, the PPyEtCN microstructures (black line) have an increased electrochemical response compared to a bulk polymer (gray line) as indicated by the stronger anodic and cathodic peaks. It is likely that this arises due to the greater number of available redox sites in the microtube film. In addition, the oxidation peak occurs at approximately 0.69 and $0.57 \mathrm{~V}$ for bulk and microtube morphologies, respectively. This shift to lower overpotentials when the microtubes are present is consistent with the tubular film possessing higher porosity, allowing easier 


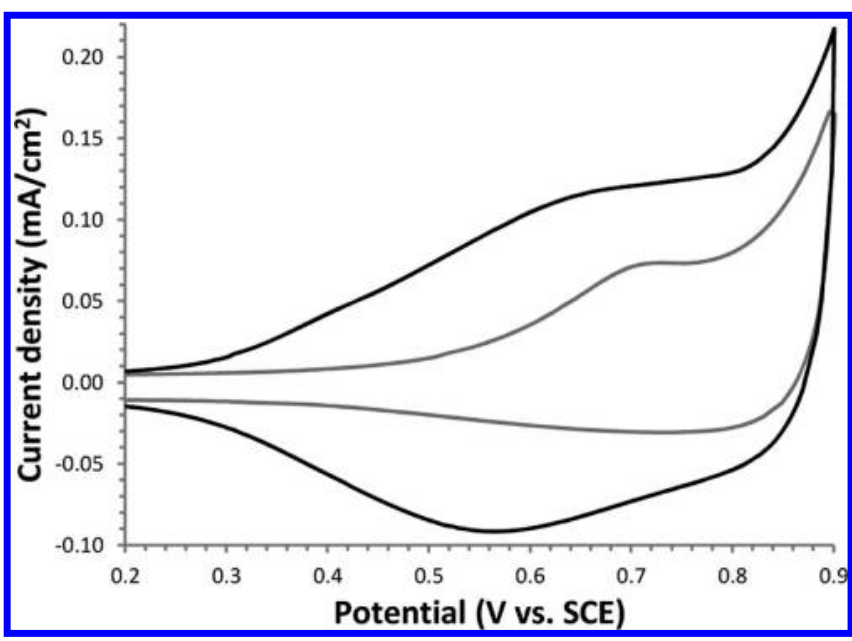

Figure 7. Cyclic voltammograms performed in $\mathrm{LiClO}_{4}(100 \mathrm{mM})$ between 0.20 and $0.85 \mathrm{~V}$ for PPyEtCN microtubes (black line) and bulk PPyEtCN (gray line). Emulsion contained PyEtCN (56 mM), $\mathrm{LiClO}_{4}(20 \mathrm{mM})$, and $\left(\mathrm{NH}_{4}\right) \mathrm{H}_{2} \mathrm{PO}_{4}(100 \mathrm{mM})$ in $10 \mathrm{~mL}$ of water/ ethanol (7:3) with $1 \mathrm{~min}$ sonication by probe. In the case of the PPyEtCN microtubes toluene $(80 \mu \mathrm{L})$ was added to form the emulsion.

movement of dopants in and out of the polymer compared to its bulk counterpart.

When the polymerization of PyEtCN was carried out from an emulsion formed using a bath sonicator, inspection of the resulting film (Figure 8) revealed interesting morphology differences compared to the films formed from probe sonicator emulsions (Figure 1). It can be seen from an early stage SEM recorded after $5 \mathrm{~min}$ at an applied potential of $0.85 \mathrm{~V}$ that the microstructures originally form in an open-tube morphology (Figure 8a). However, as polymerization continues, the opening of the tubes grow toward the center and taper completely closed (Figure $8 \mathrm{~b}$ ). TEM analysis was performed on the smaller and thinner walled microcontainers which the electron beam could penetrate, and it is apparent that a cavity remains near the base of the structure (Figure $8 \mathrm{c}$ ). As we have discussed previously, since the toluene is strongly adsorbed to the electrode surface, polymerization proceeds to close over the toluene droplet. This makes these materials a potential candidate for entrapping hydrophobic compounds within a conducting polymer microcontainer, with the advantage of being anchored to an electrode surface.

To investigate the versatility of the methodology developed to grow PPyEtCN microstructures, studies were carried out using pyrrole and 3,4-ethylenedioxythiophene. These monomers have differing solubilities in water corresponding to $2.7 \times$ $10^{-2}, 2.6 \times 10^{-1}$, and $7.8 \times 10^{-3} \mathrm{~mol} / \mathrm{L}$ at $25^{\circ} \mathrm{C}$ for PyEtCN, pyrrole, and 3,4-ethylenedioythiophene, respectively. ${ }^{45}$ Electropolymerization from the emulsions formed upon probe sonication of both pyrrole and 3,4-ethylenedioxythiophene resulted in the formation of hollow polymer microstructures on the electrode surface (Figure 9). There are some noticeable differences in the morphologies of the resultant polymers; however, this can be expected due to the different characteristic properties of each monomer, particularly their solubilities in water and ease of oxidation. These will affect the partition of the monomer between the continuous and dispersed phase of the emulsion and the rate of polymerization at a given applied potential, respectively. Therefore, this surfactant-free electrochemical procedure which couples acoustic emulsification with a toluene template approach can be used to form microstructures of a range of conducting polymers, regardless of the differing water solubilities of their monomer analogues. In addition, it was observed during the studies on PyEtCN that when the polymerization mixture was exposed to longer acoustic excitation times that the emulsion changed from being opaque to transparent. Separation back to the original multiphasic system was not observed over several days. This indicates the formation of a nanoemulsion and further studies

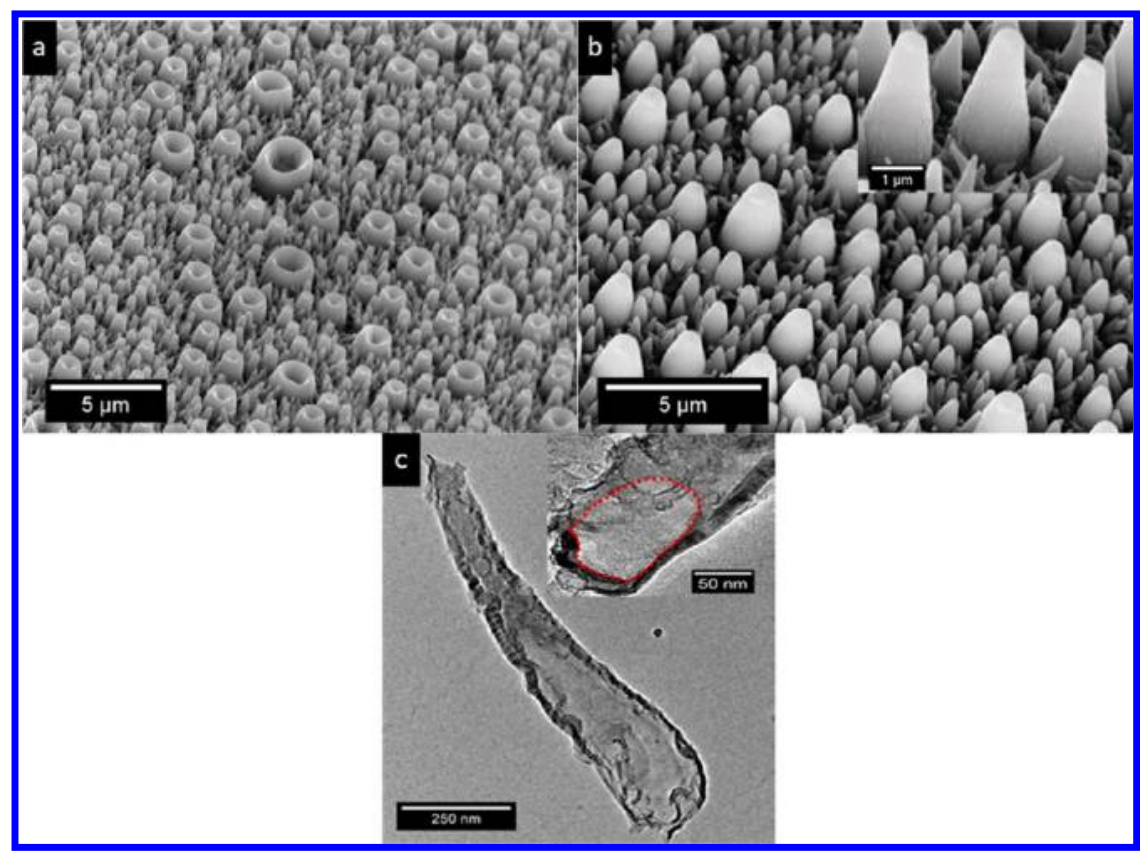

Figure 8. SEM micrographs of PPyEtCN polymers grown at $0.85 \mathrm{~V}$ for (a) $5 \mathrm{~min}$, (b) $30 \mathrm{~min}$, and (c) corresponding TEM; inset magnification of base area of tube with hollow cavity highlighted in red. Emulsion contained PyEtCN $(75 \mathrm{mM}), \mathrm{LiClO}_{4}(20 \mathrm{mM}),\left(\mathrm{NH}_{4}\right) \mathrm{H}_{2} \mathrm{PO}_{4}(100 \mathrm{mM})$, and toluene $(60 \mu \mathrm{L})$ in $10 \mathrm{~mL}$ of water/ethanol (7:3) with $1 \mathrm{~min}$ sonication by bath. 


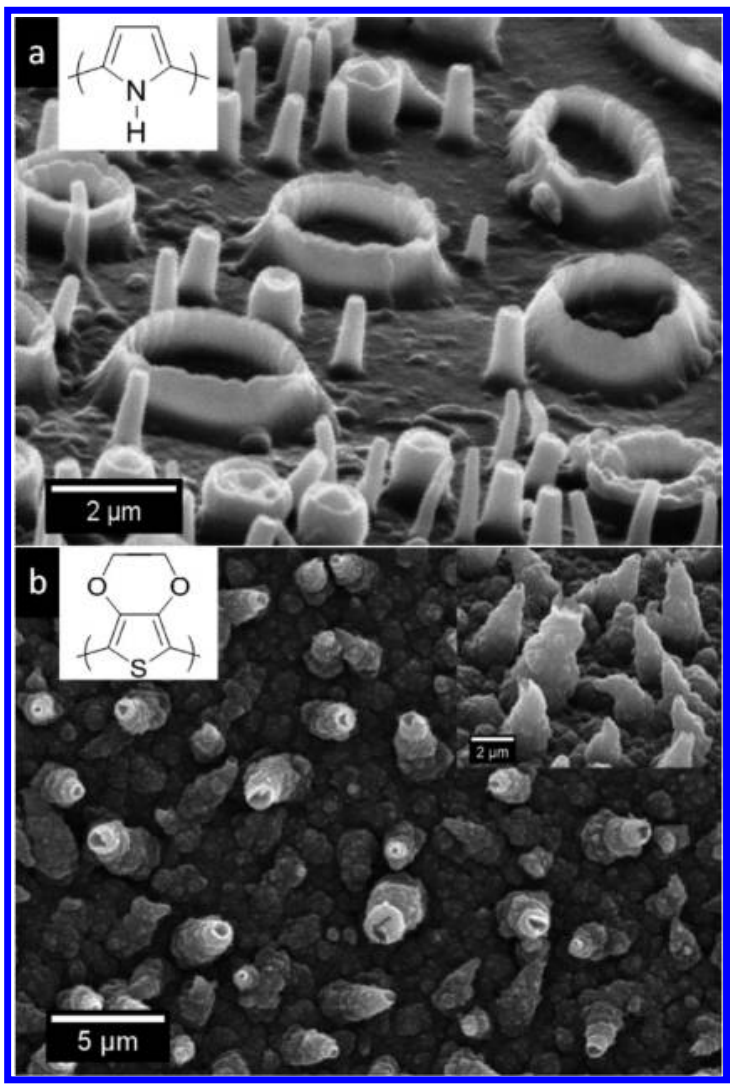

Figure 9. SEM micrograph of microstructures deposited at 0.85 and $1.05 \mathrm{~V}$ for (a) polypyrrole and (b) poly(3,4-ethylenedioxythiophene), respectively. Emulsion contained corresponding monomer $(38 \mu \mathrm{L})$, $\mathrm{LiClO}_{4}(20 \mathrm{mM})$, and toluene $(80 \mu \mathrm{L})$ in $10 \mathrm{~mL}$ of water/ethanol (7:3) with $45 \mathrm{~s}$ sonication by probe. The pyrrole solution contained $\left(\mathrm{NH}_{4}\right) \mathrm{H}_{2} \mathrm{PO}_{4}(300 \mathrm{mM})$ and the poly(3,4-ethylenedioxythiophene) solution contained $\left(\mathrm{NH}_{4}\right) \mathrm{H}_{2} \mathrm{PO}_{4}(100 \mathrm{mM})$.

will now be carried out using this system to investigate the possibility of growing hollow nanotubes of PPyEtCN and other monomers.

\section{CONCLUSIONS}

We have developed a facile means of growing novel $\mathrm{N}$ substituted polypyrrole (PPyEtCN) hollow microtubes and microcontainers attached at an electrode surface. A toluene soft template approach, which has previously been used in chemical oxidation methodology, has been successfully adapted to an electrochemical polymerization procedure. The method of sonication, applied potential, and electrolyte mixture have been shown to have a significant effect on the morphology of the final structures. The polymerization growth profiles indicate that the role of the mixed electrolyte system $\left(\mathrm{LiClO}_{4}\right.$ and $\left.\left(\mathrm{NH}_{4}\right) \mathrm{H}_{2} \mathrm{PO}_{4}\right)$ is to allow fast polymer nucleation followed by slow propagation, leading to the formation of vertically aligned structures. The microtube films displayed an increased electrochemical response compared to the bulk films and possessed superhydrophilic properties. Toluene microdroplets have been entrapped within the microcontainers, and so this methodology has the potential to entrap species close to the electrode surface. Furthermore, the procedure described within has also been proven to form microstructures for both pyrrole and 3,4-ethylenedioythiophene. Therefore, it should be applicable for growing a range of microstructures for other conducting polymers.

\section{ASSOCIATED CONTENT}

\section{S Supporting Information}

FTIR spectra for PPyEtCN, PPy, and poly(3,4-ethylenedioythiophene) microtube films; EDX data of PPyEtCN microtube films. This material is available free of charge via the Internet at http://pubs.acs.org.

\section{AUTHOR INFORMATION}

\section{Corresponding Author}

*E-mail conor.p.mccarthy@nuim.ie.

\section{Author Contributions}

The manuscript was written through contributions of all authors. All authors have given approval to the final version of the manuscript.

\section{Notes}

The authors declare no competing financial interest.

\section{ACKNOWLEDGMENTS}

The authors thank Noel Williams for his technical expertise as well as Dr. Jennifer McManus and Urszula Migas for performing all light microscopy experiments. This project is funded as part of the Science, Technology, Research and Innovation for the Environment (STRIVE) Programme 20072013 (Awards 2007-DRP-1-S5 and 2009-ET-MS-8-S2). The programme is financed by the Irish Government under the National Development Plan 2007-2013, and it is administered on behalf of the DECLG by the Environmental Protection Agency (EPA). The authors acknowledge the support of the Tyndall National Institute. This support was provided through the Science Foundation Ireland-funded National Access Programme (Project NAP 353).

\section{REFERENCES}

(1) Long, Y.-Z.; Li, M.-M.; Gu, C.; Wan, M.; Duvail, J.-L.; Liu, Z.; Fan, Z. Prog. Polym. Sci. 2011, 36, 1415-1442.

(2) Uemura, T.; Kadowaki, Y.; Yanai, N.; Kitagawa, S. Chem. Mater. 2009, 21, 4096-4098.

(3) Wang, Y.; Angelatos, A. S.; Caruso, F. Chem. Mater. 2008, 20, $848-858$.

(4) Fickert, J.; Makowski, M.; Kappl, M.; Landfester, K.; Crespy, D. Macromolecules 2012, 45, 6324-6332.

(5) Li, G.; Li, Y.; Li, Y.; Peng, H.; Chen, K. Macromolecules 2011, 44, 9319-9323.

(6) Bajpai, V.; He, P.; Dai, L. Adv. Funct. Mater. 2004, 14, 145-151.

(7) Zhou, C.; Han, J.; Guo, R. Macromolecules 2009, 42, 1252-1257.

(8) Johanson, U.; Marandi, M.; Tamm, T.; Tamm, J. Electrochim. Acta 2005, 50, 1523-1528.

(9) Dziewoński, P. M.; Grzeszczuk, M. J. Phys. Chem. B 2010, 114, $7158-7171$.

(10) George, P. M.; Lyckman, A. W.; LaVan, D. A.; Hegde, A.; Leung, Y.; Avasare, R.; Testa, C.; Alexander, P. M.; Langer, R.; Sur, M. Biomaterials 2005, 26, 3511-3519.

(11) Gao, W.; Sattayasamitsathit, S.; Uygun, A.; Pei, A.; Ponedal, A.; Wang, J. Nanoscale 2012, 4, 2447-2453.

(12) Surdo, S.; Strambini, L. M.; Malitesta, C.; Mazzotta, E.; Barillaro, G. Electrochem. Commun. 2012, 14, 1-4.

(13) Cui, Y.; Wen, Z.; Liang, X.; Lu, Y.; Jin, J.; Wu, M.; Wu, X. Energy Environ. Sci. 2012, 5, 7893-7897.

(14) Roy, C. J.; Chorine, N.; De Geest, B. G.; De Smedt, S.; Jonas, A. M.; Demoustier-Champagne, S. Chem. Mater. 2012, 24, 1562-1567.

(15) Mangeney, C.; Bousalem, S.; Connan, C.; Vaulay, M.-J.; Bernard, S.; Chehimi, M. M. Langmuir 2006, 22, 10163-10169.

(16) Kijewska, K.; Blanchard, G. J.; Szlachetko, J.; Stolarski, J.; Kisiel, A.; Michalska, A.; Maksymiuk, K.; Pisarek, M.; Majewski, P.; Krysiński, P.; Mazur, M. Chem.-Eur. J. 2012, 18, 310-320. 
(17) Qu, L.; Shi, G.; Yuan, J.; Han, G.; Chen, F. E. J. Electroanal. Chem. 2004, 561, 149-156.

(18) Qu, L.; Shi, G.; Chen, F. E.; Zhang, J. Macromolecules 2003, 36, 1063-1067.

(19) Qu, L.; Shi, G. J. Polym. Sci., Polym. Chem. 2004, 42, 3170-3177.

(20) Huang, J.; Quan, B.; Liu, M.; Wei, Z.; Jiang, L. Macromol. Rapid Commun. 2008, 29, 1335-1340.

(21) Skotheim, T. A.; Reynolds, J. R. Handbook of Conducting Polymers; CRC Press: Boca Raton, FL, 2007.

(22) Parakhonskiy, B.; Andreeva, D.; Mohwald, H.; Shchukin, D. G. Langmuir 2009, 25, 4780-4786.

(23) Li, C.; Bai, H.; Shi, G. Chem. Soc. Rev. 2009, 38, 2397-2409.

(24) McCarthy, C. P.; McGuinness, N. B.; Alcock-Earley, B. E.; Breslin, C. B.; Rooney, A. D. Electrochem. Commun. 2012, 20, 79-82.

(25) Teixeira-Dias, B.; Alemán, C.; Estrany, F.; Azambuja, D. S.; Armelin, E. Electrochim. Acta 2011, 56, 5836-5843.

(26) Fabregat, G.; Alemán, C.; Casas, M. T.; Armelin, E. J. Phys. Chem. B 2012, 116, 5064-5070.

(27) Martí, M.; Fabregat, G.; Estrany, F.; Alemán, C.; Armelin, E. J. Mater. Chem. 2010, 20, 10652-10660.

(28) Um, H.-J.; Kim, M.; Lee, S.-H.; Min, J.; Kim, H.; Choi, Y.-W.; Kim, Y.-H. Talanta 2011, 84, 330-334.

(29) Fabregat, G.; Córdova-Mateo, E.; Armelin, E.; Bertran, O.; Alemán, C. J. Phys. Chem. C 2011, 115, 14933-14941.

(30) Sravendra, R.; Niranjan, K.; Jae Whan, C.; Young, H. K. Nanotechnology 2008, 19, 495707.

(31) Kwon, O. S.; Park, S. J.; Jang, J. Biomaterials 2010, 31, 47404747.

(32) Shida, N.; Ishiguro, Y.; Atobe, M.; Fuchigami, T.; Inagi, S. ACS Macro Lett. 2012, 1, 656-659.

(33) Wang, J.; Xu, Y.; Yan, F.; Zhu, J.; Wang, J. J. Power Sources 2011, 196, 2373-2379.

(34) Al-Mashat, L.; Debiemme-Chouvy, C.; Borensztajn, S.; Wlodarski, W. J. Phys. Chem. C 2012, 116, 13388-13394.

(35) Zang, J.; Li, C. M.; Bao, S.-J.; Cui, X.; Bao, Q.; Sun, C. Q. Macromolecules 2008, 41, 7053-7057.

(36) Gao, Y.; Zhao, L.; Li, C.; Shi, G. Polymer 2006, 47, 4953-4958.

(37) Gao, Y.; Zhao, L.; Bai, H.; Chen, Q.; Shi, G. J. Electroanal. Chem. 2006, 597, 13-18.

(38) Kępińska, D.; Blanchard, G. J.; Krysiński, P.; Stolarski, J.; Kijewska, K.; Mazur, M. Langmuir 2011, 27, 12720-12729.

(39) Mazur, M. Langmuir 2008, 24, 10414-10420.

(40) Lad, V. N.; Murthy, Z. V. P. Ind. Eng. Chem. Res. 2012, 51, $4222-4229$.

(41) Catherine, D.-C. Electrochem. Commun. 2009, 11, 298-301.

(42) Liang, L.; Liu, J.; Windisch, J. C. F.; Exarhos, G. J.; Lin, Y. Angew. Chem., Int. Ed. 2002, 41, 3665-3668.

(43) Zhou, M.; Heinze, J. J. Phys. Chem. B 1999, 103, 8443-8450.

(44) Weiss, Z.; Mandler, D.; Shustak, G.; Domb, A. J. J. Polym. Sci., Polym. Chem. 2004, 42, 1658-1667.

(45) Scifinder. Substance experimental properties. 